\title{
Carbon Nanotube Planted on Ni-Based Alloy in Microbial Fuel Cell
}

\author{
Chin-Tsan Wang, ${ }^{1}$ Yan-Ming Chen, ${ }^{2}$ Zhao-Qin Qi, ${ }^{3}$ and Yung-Chin Yang ${ }^{2}$ \\ ${ }^{1}$ Department of Mechanical and Electro-Mechanical Engineering, National I-Lan University, I-Lan 260, Taiwan \\ ${ }^{2}$ Department of Materials and Mineral Resources Engineering, National Taipei University of Technology, Taipei 106, Taiwan \\ ${ }^{3}$ Doosan Infracore Co. Ltd., Yantai 264005, Shandong, China
}

Correspondence should be addressed to Chin-Tsan Wang; ctwang@niu.edu.tw

Received 2 April 2013; Revised 19 September 2013; Accepted 19 September 2013

Academic Editor: Andrey Miroshnichenko

Copyright (c) 2013 Chin-Tsan Wang et al. This is an open access article distributed under the Creative Commons Attribution License, which permits unrestricted use, distribution, and reproduction in any medium, provided the original work is properly cited.

The improvement of electrode materials used in microbial fuel cell (MFC) technology for enhancing the power performance of MFCs has attracted more and more attention lately. In this study, an new electrode material with a carbon nanotube planted on an Ni-based alloy substrate is applied to the MFC. Results show that a well-synthesized, straight CNT electrode performs the best, with a high open circuit voltage of $0.82 \mathrm{~V}$ and a maximum power density of $2.31 \mathrm{~W} / \mathrm{m}^{2}$. It is believed that this new kind of electrode will have a promising future in the technology of power generation from MFCs.

\section{Introduction}

The microbial fuel cell (MFC) is a rising form of power technology, as its use in the wastewater treatment process can become a method of capturing energy in the form of electricity or hydrogen gas, rather than being a drain on electrical energy [1]. However, a high internal resistance still exists in the MFC [2,3], with a low power density appearing in MFCs that is needed to be overcome. Recent studies have shown that an MFC must be first able to reduce the loss in polarization effectively [4]. Microbial inoculums [5], chemical substrates [6], proton exchange materials [7], internal and external cell resistance [8], ionic solution strength [9], electrode materials [10], and operation conditions and configuration [1] have been continued to be studied. Among all these influencing factors in MFCs, the effect of electrode material on the power performance of MFCs is most significant [11]. This is because an inferior material feature of an electrode, mainly resulting from a difficult electron transfer between the bacteria and the electrode, will cause a low power output from MFCs [11].

Nowadays, carbon nanotubes (CNTs) have exhibited great potential as electrode materials in fuel cell applications due to their high surface-to-volume ratio and unique electrical and mechanical properties [12]. There has been little research done of MFCs in spite of the fact that the CNTs in the composite substrate can also facilitate the formation of biofilm in them, which is necessary for electron transfer via c-type cytochromes and nanowires [13]. In addition, several reports related to the CNT were also utilized to modify the anode electrode materials in MFCs [14-17]. The study by Sun et al., 2010, indicated that a multilayer modification would provide a free-standing three-dimensional network structure of interwoven nanotubes. This would enable a more specific surface area for anodic bacteria to anchor and decrease the interfacial charge transfer resistance from 1163 to $258 \Omega$. The report by Xie et al. shows that the conformability of coating microscale porous CNT layers would provide a strong interaction between the microbial biofilms, thus facilitating electron transfer from exoelectrogens to the CNTtextile anodes [18]. Mink et al. pointed out that the anode of multiwalled carbon nanotubes in MFCs would outperform the others (kinds of gold and nickel anode resp.,) in both current and power densities displaying between 6 to 20 times better performance [19].

However, the CNT was usually directly grown on the surface of carbon materials based on the consideration of the anticorrosion ability of carbon material in MFCs. In fact, the electrical conductivity of carbon material is still lower 
than that of metal materials. The anticorrosion feature of Nibased alloys with a more than pure metal has been confirmed [20, 21]. Therefore, an Ni-based alloy material with good electricity conductivity, and anticorrosion property would be used as a substrate and the anode electrode of an MFC. This would be so as to plant the carbon nanotube on it to produce a better power performance and then compare it with the case of an Ni-based alloy without a CNT in this study.

\section{Experimental Section}

2.1. Preparation of Ni-Based Alloy with CNT. The CNT was planted on the metal alloy substrate, which consisted of Si, $\mathrm{Ni}, \mathrm{Al}$, and Ti. Layers of titanium (Ti), aluminum (Al), and nickel (Ni) were used for adhesion, conduction, and as a catalytic layer, respectively, and then sequentially deposited on a (100) Si wafer. The CNTs were synthesized in a thermal CVD system by introducing a mixture of ammonia $\left(\mathrm{NH}_{3}\right)$ and ethylene $\left(\mathrm{C}_{2} \mathrm{H}_{4}\right)$ at about $800^{\circ} \mathrm{C}$ for 5-20 minutes at atmospheric pressure [20]. Since the alignment of CNTs can be controlled by the thickness of the catalytic layer, namely, the Ni layer [22], the thickness of the $\mathrm{Ti}$ and $\mathrm{Al}$ layers were kept at $75 \mathrm{~nm}$ and $10 \mathrm{~nm}$, respectively. Therefore, vertically aligned CNTs can be achieved by depositing $10 \mathrm{~nm}$ Ni layer; in contrast, curved CNTs can be achieved at an Ni layer thickness of $5 \mathrm{~nm}$.

2.2. MFC Construction and Operation. The reactors were assembled by connecting two cubic-shaped chambers made of PMMA and separated by a proton exchange membrane (Nafion 117). The total volume of each chamber was $150 \mathrm{~cm}^{3}$. The single-faced CNT modified metal alloy plate $(1.8 \mathrm{~cm}$ $\times 1 \mathrm{~cm})$ was used as the anode electrode, compared with the metal alloy plate without the CNT. Carbon felt $(4 \mathrm{~cm} \times$ $4.5 \mathrm{~cm} \times 0.6 \mathrm{~cm})$ was chosen as the cathode electrode and pretreated in a hot $\mathrm{H}_{2} \mathrm{O}_{2}\left(10 \%, 90^{\circ} \mathrm{C}\right)$ solution for $3 \mathrm{hrs}$ to develop local quinine sites on the carbon surface to improve the anode biocompatibility [23]. In the study, three sets were used: MFC-1 (Ni-based alloy plate without CNT), MFC2 (Ni-based alloy plate with a single-faced straight CNT), and MFC-3 (Ni-based alloy plate with a single-faced curved CNT). In the anode, $130 \mathrm{~mL}$ of dairy wastewater, fermented for more than three years, was filled as the anolyte, while in the cathode, a $130 \mathrm{~mL}$ potassium ferricyanide solution of $0.05 \mathrm{~mol} / \mathrm{L}$ was filled as the catholyte.

2.3. Electrochemical and Microscopy Analysis. Polarization curves were measured on the Electricity Workstation (Jiehan Technology Corporation, ECW-5000/5600) at a scan rate of $1 \mathrm{mV} / \mathrm{s}$ two days after the MFCs start-up time, and a $P=I V$ formula was applied to calculate the power, $P$, of MFCs, where $I$ is current and $V$ is the voltage.

After measuring the polarization curves, the MFCs were tested under room temperature with a $1 \mathrm{k} \Omega$ external resistance; the voltage output was acquired at 3-minute intervals by an automatic data acquisition system (Jiehan 5020, Taiwan) connected to a computer. The internal resistance was calculated under a maximum power density according to

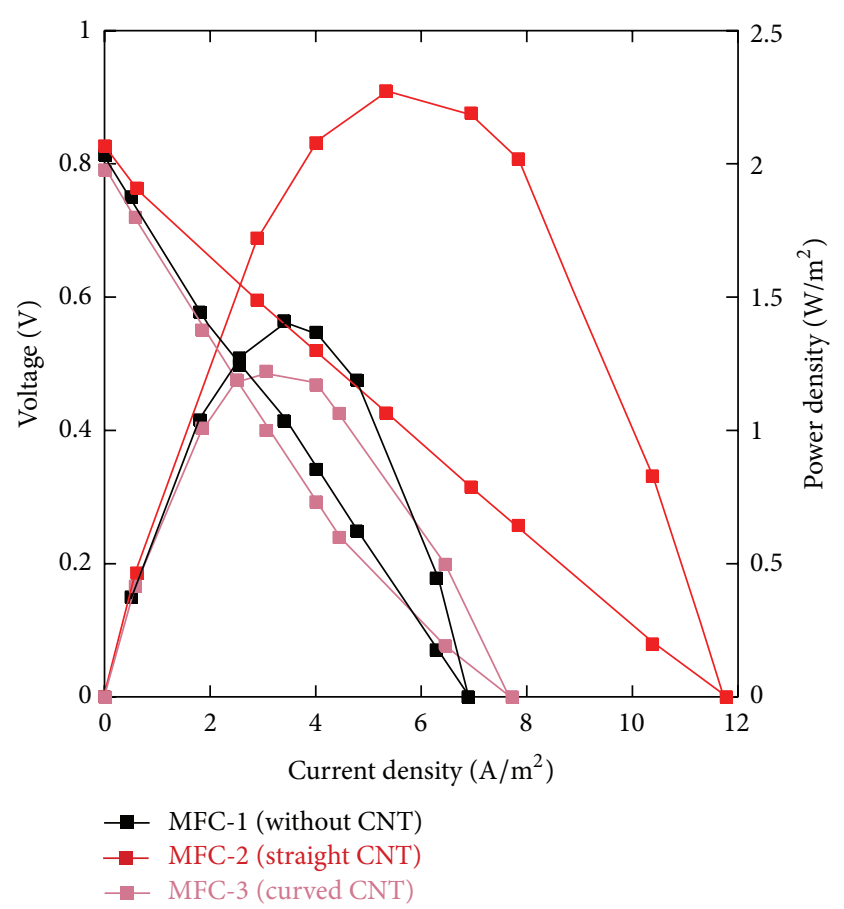

FIgURE 1: Power density and polarization curve of the three MFCs.

Ohm's Law $\left(R_{\text {int }}=U / I\right)$, where $I$ refers to current and $U$ to voltage. $R_{\text {int }}$ indicates Ohm's resistance.

The morphology of the CNT was observed with a scanning electron microscopy (SEM, JEOLJSM-6330F).

\section{Results and Discussion}

In this study, cases of the anode electrode with/without CNT were investigated. Two days after the MFCs start-up time, the power density and the polarization curves were measured and are shown in Figure 1. Additionally, the constant-load discharge curve was measured and is shown in Figure 2.

As seen in Figure 1, it can be observed that the open circuit voltage (OCV) and the maximum power density of MFC-2 (Ni-based alloy plate with the straight CNT) were $0.82 \mathrm{~V}$ and $2.31 \mathrm{~W} / \mathrm{m}^{2}$, which was higher than those of MFC1 (Ni-based alloy plate without CNT) by 1.04 times and 1.85 times, respectively. This is due to the fact that the Ni-based alloy plate with the straight CNT not only had a high surfaceto-volume ratio $[12,24]$ but also could facilitate the formation of a biofilm [13], which reduced the anode charge transfer resistance [24-26]. Furthermore, it can be observed that the $I-V$ curve of MFC-2 has a smaller slope at the middle current density area. This is due to the fact that the CNTs have the ability to enhance direct electron transfer $[18,27,28]$, which can reduce the ohmic resistance of $\mathrm{MFC}-2$, and so the power generation of MFC-2 (Ni-based alloy plate with the straight $\mathrm{CNT})$ performed the best.

Unexpectedly, MFC-3 (Ni-based alloy plate with a singlefaced curved CNT) showed an OCV of $0.81 \mathrm{~V}$, which was higher than that of MFC-1 (Ni-based alloy plate without 


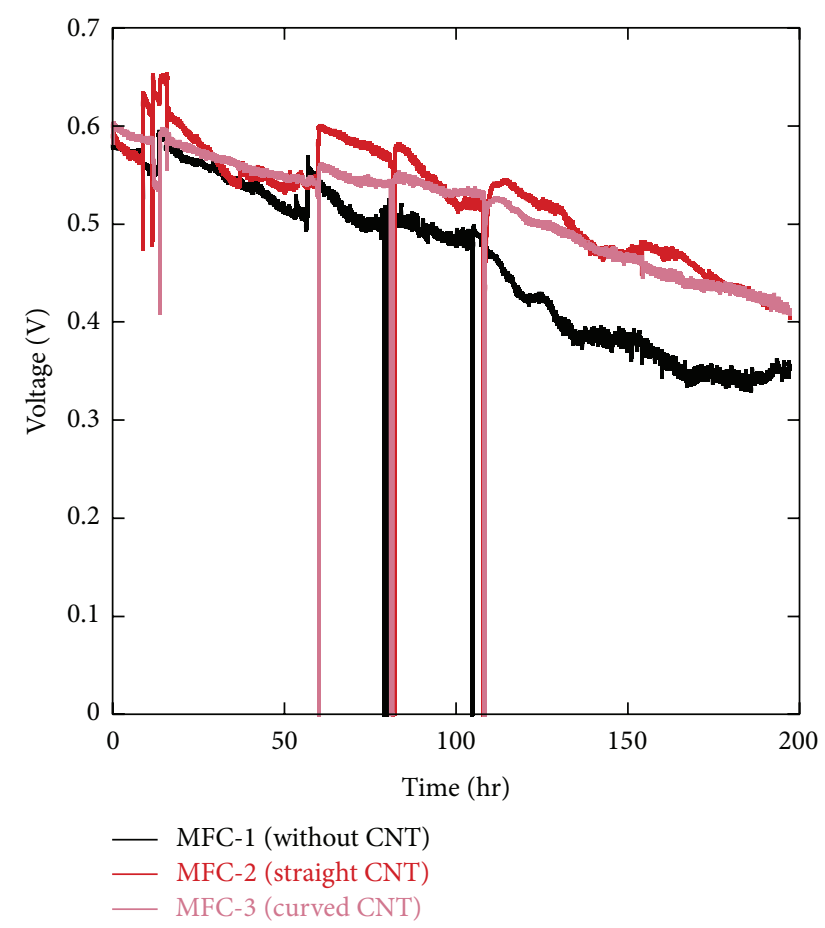

FIGURE 2: The constant-load discharge curve of the three MFCs.

CNT) by 1.03 times, but the maximum power density was lower than that of MFC-1 $\left(1.37 \mathrm{~W} / \mathrm{m}^{2}\right)$ by 1.1 times. This is because of the substrate crossover and the unwanted side reactions in the cathode compartment [29].

As seen from Figure 2, the output voltage decreased as time passed. During the testing, the operation of measuring COD caused a disturbance in the dairy wastewater every two days, so the voltage curve was not as smooth as the polarization curve. However, the results observed from Figure 2, which shows that the voltage of MFC-2 and MFC3 was higher than that of MFC-1 and also more stable [24]. This is due to the fact that the alloy substrate surface is very smooth, which would make microbial colonization difficult. Hence, during the microbiological degradation, few microbes could land on the electrode, so the available electron was hard to collect and transfer. On the other hand, the nanostructured composites had a faster reaction rate [14] and strong electrode-biofilm interaction [18] and the highly conductive nanotube network served as nanowires to facilitate the electron transfer between the microbes and the electrodes [12]. In addition, the voltage of MFC-2 was higher and longer lasting than that of MFC-3; this is due to the fact that the electron pathway of the straight CNT was shorter than that of the curved CNT, meaning that the straight CNT could reduce more ohmic resistance. Also, as displayed in Figures 3 and 4, the connection between the curved CNT and the alloy substrate is not as exact as that between the straight $\mathrm{CNT}$ and the alloy substrate. The connection between the straight CNT and the substrate is good, so the generated electrons are able to move toward the alloy substrate without crossing through the interface. The poor connection could

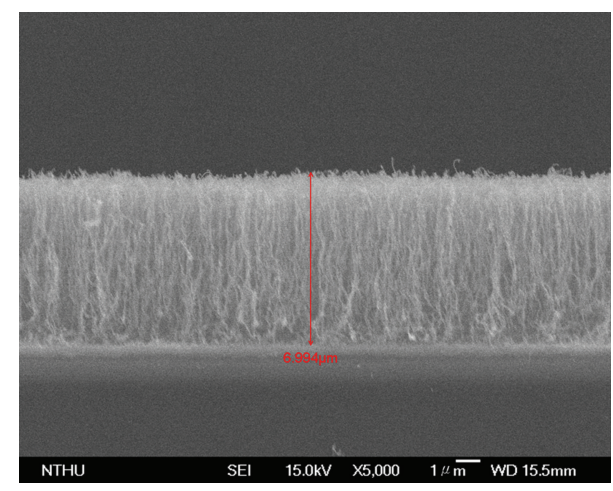

Figure 3: Morphology of the straight CNT on the alloy substrate.

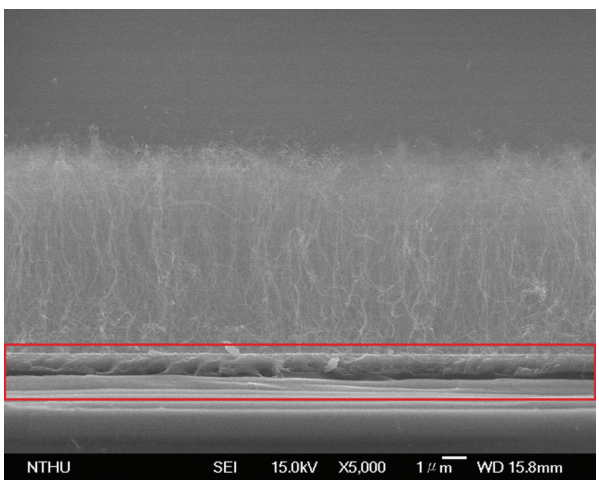

FIGURE 4: Morphology of the curved CNT on the alloy substrate.

bring out a higher contact resistance and a faster polarization and finally cause the failure of the MFC. Compared with other studies, the maximum power density of using an Ni-based alloy plate with the straight CNT as the anode was $2.31 \mathrm{~W} / \mathrm{m}^{2}$, which was higher than that of the CNT/PANI anode by 55 times [14] and higher than that of the 3D CNT textile anode by 1.94 times [18] and higher than that of the $\mathrm{Mo}_{2} \mathrm{C} / \mathrm{CNTs}$ anode by 2.2 times [13]. So, this evidence shows that an $\mathrm{Ni}$-based alloy plate with a straight CNT as the electrode material can enhance electrical properties significantly and so be useful to the improvement of the electrode anode in MFCs.

\section{Conclusions}

It can be concluded that metal alloys will make promising electrode materials for MFCs and that CNT planted technology could enhance the power performance of electrodes: OCV, limiting current density, and power density. In this study, the electrode planted with a straight CNT obtained an optimal power performance of open circuit voltage (OCV) of $0.82 \mathrm{~V}$ and a maximum power density of $2.31 \mathrm{~W} / \mathrm{m}^{2}$. In the future, a better modified CNT will have promising developments, especially for wider use in the power generation field.

\section{Conflict of Interests}

Chin-Tsan Wang and his coauthors do not have any direct financial relation to the trademarks mentioned in the paper. 


\section{Acknowledgments}

The authors would like to thank the National Science Council of the Republic of China, Taiwan, for financially supporting this research under Contract nos. NSC-101-2221-E-197006, NSC-101-2622-E-197-004-CC3, and NSC-102-2623-E197-001-ET. The authors would also like to thank Dr. Peng Hsien-Chin for supporting the experimental substrate and the National I-Lan University for financially supporting this research under Contract no. 101TGA-2B.

\section{References}

[1] B. E. Logan, Microbial Fuel Cells, John Wiley \& sons, Inc, Hoboken, NJ, USA, 2008.

[2] P. Liang, X. Huang, M.-Z. Fan, X.-X. Cao, and C. Wang, "Composition and distribution of internal resistance in three types of microbial fuel cells," Applied Microbiology and Biotechnology, vol. 77, no. 3, pp. 551-558, 2007.

[3] P. T. Ha, H. Moon, B. H. Kim, H. Y. Ng, and I. S. Chang, "Determination of charge transfer resistance and capacitance of microbial fuel cell through a transient response analysis of cell voltage," Biosensors and Bioelectronics, vol. 25, no. 7, pp. 16291634, 2010.

[4] Y. M. Chen, C. T. Wang, Y. C. Yang, and W. J. Chen, "Application of aluminum-alloy mesh composite carbon cloth for the design of anode/cathode electrodes in Escherichia coli microbial fuel cell," International Journal of Hydrogen Energy, vol. 38, pp. 11311137, 2013.

[5] C.-T. Wang, W.-J. Chen, and R.-Y. Huang, "Influence of growth curve phase on electricity performance of microbial fuel cell by Escherichia coli," International Journal of Hydrogen Energy, vol. 35, no. 13, pp. 7217-7223, 2010.

[6] D. Pant, G. Van Bogaert, L. Diels, and K. Vanbroekhoven, "A review of the substrates used in microbial fuel cells (MFCs) for sustainable energy production," Bioresource Technology, vol. 101, no. 6, pp. 1533-1543, 2010.

[7] J. R. Kim, S. Cheng, S. E. Oh, and B. E. Logan, "Power generation using different cation, anion, and ultrafiltration membranes in microbial fuel cells," Environmental Science and Technology, vol. 41, no. 3, pp. 1004-1009, 2007.

[8] P. Aelterman, M. Versichele, M. Marzorati, N. Boon, and W. Verstraete, "Loading rate and external resistance control the electricity generation of microbial fuel cells with different threedimensional anodes," Bioresource Technology, vol. 99, no. 18, pp. 8895-8902, 2008.

[9] H. Liu, S. Cheng, and B. E. Logan, "Power generation in fed-batch microbial fuel cells as a function of ionic strength, temperature, and reactor configuration," Environmental Science and Technology, vol. 39, no. 14, pp. 5488-5493, 2005.

[10] Y. Feng, X. Shi, X. Wang et al., "Effects of sulfide on microbial fuel cells with platinum and nitrogen-doped carbon powder cathodes," Biosensors and Bioelectronics, vol. 35, no. 1, pp. 413415, 2012.

[11] M. Ghasemi, W. R. W. Daud, S. H. Hassan et al., "Nanostructured carbon as electrode material in microbial fuel cells: a comprehensive review," Journal of Alloys and Compounds, vol. 580, pp. 245-255, 2013.

[12] H. M. Wang, Z. C. Wu, A. Plaseied et al., "Carbon nanotube modified air-cathodes for electricity production in microbial fuel cells," Journal of Power Sources, vol. 196, no. 18, pp. 74657469, 2011.
[13] Y. Wang, B. Li, D. Cui, X. Xiang, and W. Li, "Nano-molybdenum carbide/carbon nanotubes composite as bifunctional anode catalyst for high-performance Escherichia coli-based microbial fuel cell," Biosensors and Bioelectronics, vol. 51, pp. 349-355, 2014.

[14] Y. Qiao, C. M. Li, S.-J. Bao, and Q.-L. Bao, "Carbon nanotube/polyaniline composite as anode material for microbial fuel cells," Journal of Power Sources, vol. 170, no. 1, pp. 79-84, 2007.

[15] H.-Y. Tsai, C.-C. Wu, C.-Y. Lee, and E. P. Shih, "Microbial fuel cell performance of multiwall carbon nanotubes on carbon cloth as electrodes," Journal of Power Sources, vol. 194, no. 1, pp. 199-205, 2009.

[16] T. Sharma, A. L. Mohana Reddy, T. S. Chandra, and S. Ramaprabhu, "Development of carbon nanotubes and nanofluids based microbial fuel cell," International Journal of Hydrogen Energy, vol. 33, no. 22, pp. 6749-6754, 2008.

[17] X. Xie, M. Ye, L. Hu et al., "Carbon nanotube-coated macroporous sponge for microbial fuel cell electrodes," Energy and Environmental Science, vol. 5, no. 1, pp. 5265-5270, 2012.

[18] X. Xie, L. Hu, M. Pasta et al., “Three-dimensional carbon nanotube-textile anode for high-performance microbial fuel cells," Nano Letters, vol. 11, no. 1, pp. 291-296, 2011.

[19] J. E. Mink and M. M. Hussain, "Sustainable design of high performance micro-sized microbial fuel cell with carbon nanotube anode and air cathode," ACS Nano, vol. 7, pp. 6921-6927, 2013.

[20] Z. Y. Juang, J. F. Lai, C. H. Weng et al., "On the kinetics of carbon nanotube growth by thermal CVD method," Diamond and Related Materials, vol. 13, no. 11-12, pp. 2140-2146, 2004.

[21] C. Du and N. Pan, "CVD growth of carbon nanotubes directly on nickel substrate," Materials Letters, vol. 59, no. 13, pp. 16781682, 2005.

[22] Y. S. Wu, F. G. Tseng, and C. H. Tsai, "Growth and characteristics of vertically-aligned carbon nanotubes by thermal CVD on various Si-based substrates for micro-DMFC," in Proceedings of the 6th International Workshop on Micro and Nanotechnologies for Power Generation and Energy Conversion Applications (PowerMEMS '06), Berkeley, Calif, USA, 2006.

[23] J. L. Liu, D. A. Lowy, R. G. Baumann, and L. M. Tender, "Influence of anode pretreatment on its microbial colonization," Journal of Applied Microbiology, vol. 102, no. 1, pp. 177-183, 2007.

[24] Y. Zou, C. Xiang, L. Yang, L.-X. Sun, F. Xu, and Z. Cao, “A mediatorless microbial fuel cell using polypyrrole coated carbon nanotubes composite as anode material," International Journal of Hydrogen Energy, vol. 33, no. 18, pp. 4856-4862, 2008.

[25] A. P. Borole, D. Aaron, C. Y. Hamilton, and C. Tsouris, "Understanding long-term changes in microbial fuel cell performance using electrochemical impedance spectroscopy," Environmental Science and Technology, vol. 44, no. 7, pp. 2740-2745, 2010.

[26] Y. Zhang, J. Sun, B. Hou, and Y. Hu, "Performance improvement of air-cathode single-chamber microbial fuel cell using a mesoporous carbon modified anode," Journal of Power Sources, vol. 196, no. 18, pp. 7458-7464, 2011.

[27] M. U. Khan, V. G. Gomes, and I. S. Altarawneh, "Synthesizing polystyrene/carbon nanotube composites by emulsion polymerization with non-covalent and covalent functionalization," Carbon, vol. 48, no. 10, pp. 2925-2933, 2010.

[28] S. K. Smart, A. I. Cassady, G. Q. Lu, and D. J. Martin, “The biocompatibility of carbon nanotubes," Carbon, vol. 44, no. 6 , pp. 1034-1047, 2006. 
[29] H. Rismani-Yazdi, S. M. Carver, A. D. Christy, and O. H. Tuovinen, "Cathodic limitations in microbial fuel cells: an overview," Journal of Power Sources, vol. 180, no. 2, pp. 683-694, 2008. 

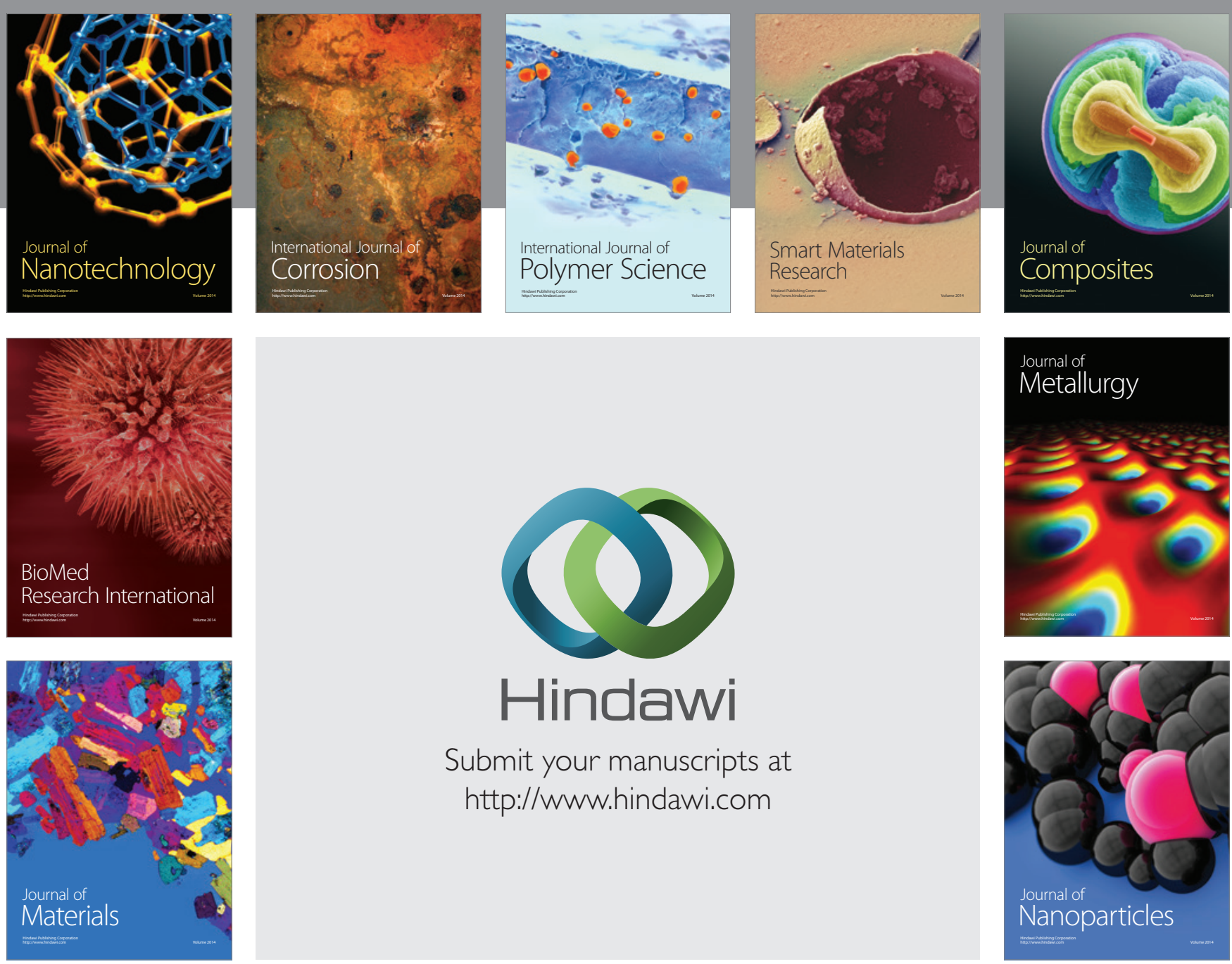

Submit your manuscripts at http://www.hindawi.com
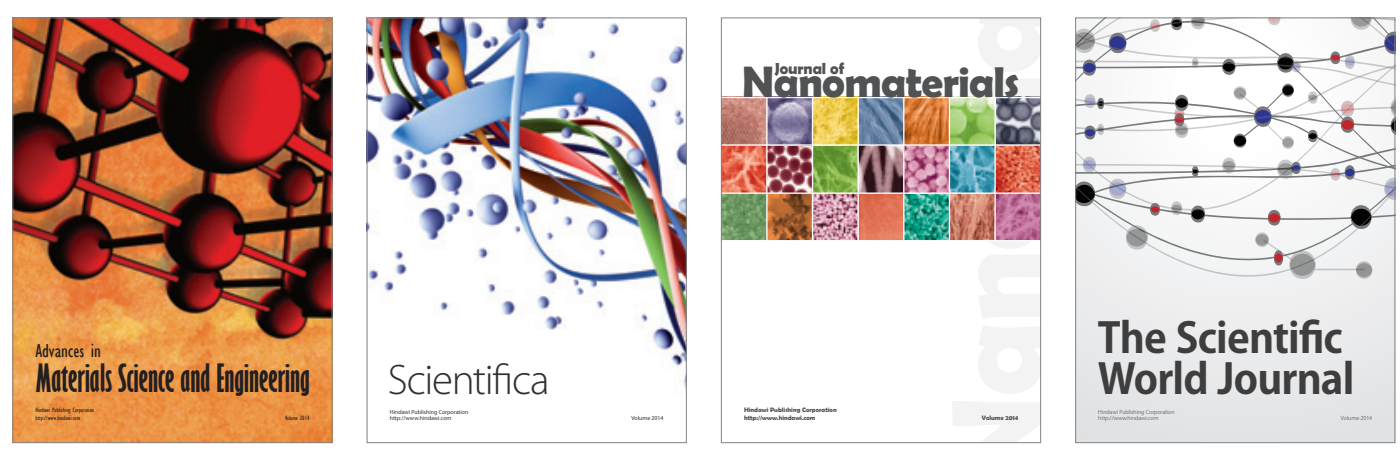

\section{The Scientific World Journal}
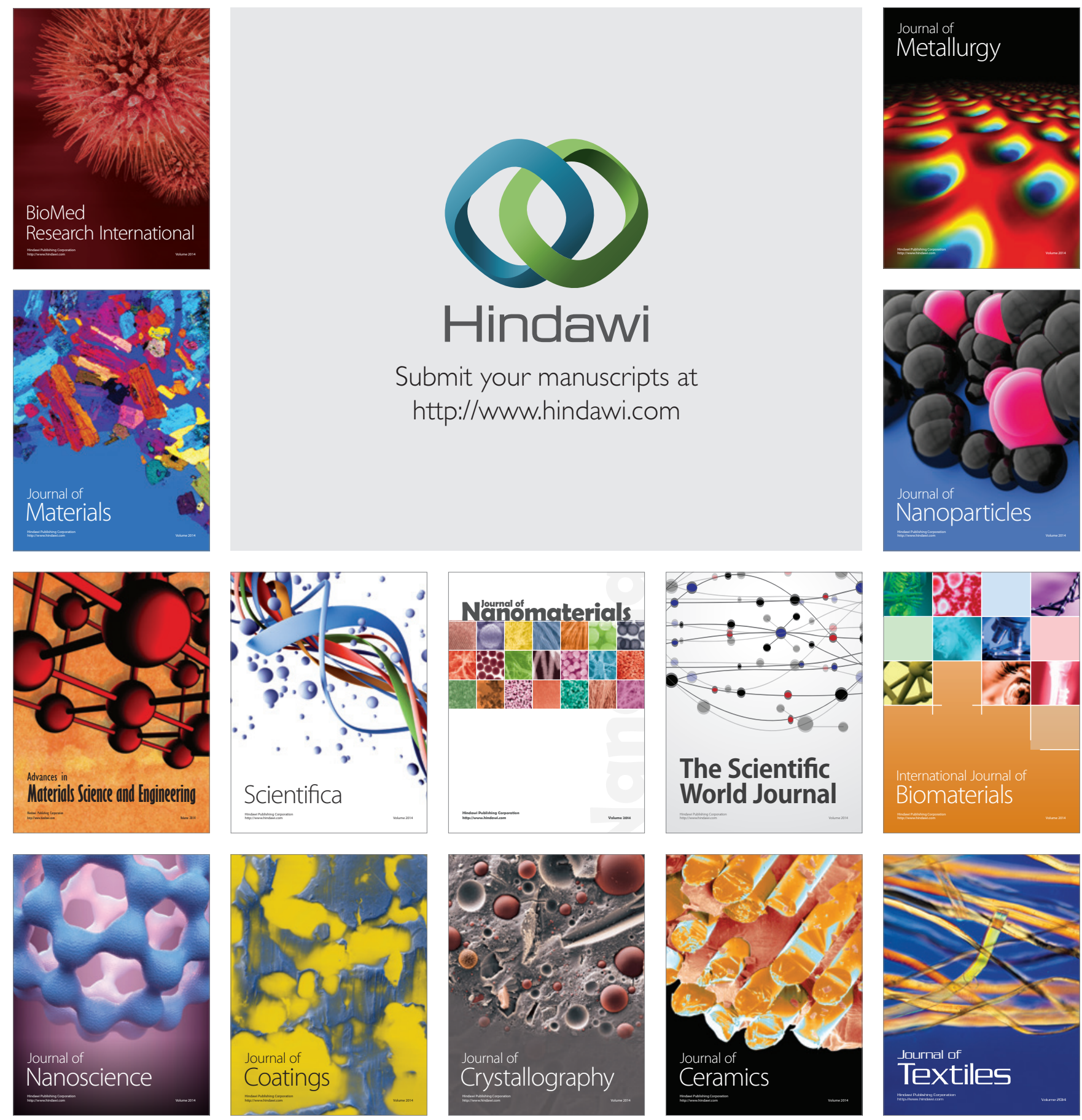